\title{
PALLIATIVE NURSE CARE - EDUCATION AND TRAINING
}

\author{
Despina Georgieva, Greta Koleva \\ Department of Healthcare, Faculty of Public Health and Healthcare, \\ Ruse University "Angel Kanchev"
}

\begin{abstract}
INTRODUCTION: Palliative care is a method which improves the quality of life via control over the typical symptoms. Subject of palliative care are patients with life-threatening diseases. The activities are subordinate to the basic principles which are directed at solving physical, mental, spiritual and social problems, as well as, assessment and treatment of the pain. The active communication and dealings with the patients' relatives are also part of the nurse's actions, who gives palliative care. The specificity of palliative care requires specialized preparation, aimed at acquiring knowledge of the sphere, as well as development of certain skills and competences. The lack of the clinical subject Palliative Medical Science is a great challenge and responsibility for the training team, to present this subject, and to teach the skills needed for the students.
\end{abstract}

AIM: Presenting the organization of training in palliative care of nurses.

MATERIAL AND METHODS: After finishing their training, the students gave a feedback via a poll. By the analysis of the results it is determined that the examined students have acquired sufficient amount of information. For the purpose of the practical training, an approbation of nursing documentation has been worked out during the exercises, wich were held in a Department of Palliative Care at the Complex Cancer Center - Ruse (CCC). The students highly evaluate the documents provided for work, and they think that by introducing them in practice, the quality of care will rise significantly, the nursing care will get easier, and consistency will be achieved.

An electronic nurse file for palliative care has been developed, which allows registration and accounting of the activities performed.

CONCLUSIONS: From the survey of the students who have undergone training in the discipline, a positive feedback is established. It appeared that they have received and absorbed a sufficient amount of information in palliative nursing care.

Keywords: training, nurse, palliative health cares, assessment of the symptoms

\footnotetext{
Address for correspondence:

Despina Georgieva

Department of Healthcare

Faculty of Public Health and Healthcare

Ruse University "Angel Kanchev"

8 Studentska Str., Ruse

e-mail:dpgeorgieva@uni-ruse.bg

phone: 0889789100
}

Received: October 15, 2016

Accepted: December 21, 2016

\section{INTRODUCTION}

According to the World Health Organization, palliative care is a method which improves the quality of life of patients and their families, who face the problem of a life-threatening disease, by preventing and relieving the pain, assessment and cure of the pain, and solving physical, psychosocial and mental problems (1). 
At the National Health Strategy, which accepts the comprehensive integrative principle, enshrined in the EU Strategy "Europe 2020", the continuously increasing costs of health care and the accretive public frustration are being reported. The question of rational use of health care is raised, so the efforts are aimed at morally acceptable conditions of lowering the expenses and optimizing the health systems (2).

Palliative medical science is part of the clinical directions, spending significant funds. Not long ago it became a medical discipline with academic studies and a clinically regulated activity. Satisfying the needs of the patients who require palliative care, an application of an integrated approach and care is needed, aimed at the physical and mental needs at the end of life, relieving the pain and the other concomitant symptoms. Palliative care can be done at the patient's home, at a hospice or at hospital.

The specificity of palliative care demands adequate professional preparation of the team of specialists, working in this field. The nurse who does palliative care has to be motivated to work in a field, which is not appealing, must have a certain mindset, and possess qualities such as patience, compassion and empathy. Health care professionals need to possess good communication techniques and skills, self-control and ability to cope with stressful situations due to daily communication with patients in terminal stages of a disease, and also with their relatives. Implementing the basic aspects and principles of palliative care requires open communication with patients and their families, helping them with taking important decisions related to supportive treatment, symptom relief and quality of life of the patient. Clear differentiation of activities and better collaboration between family members is required.

The training of students in the subject of Palliative Nurse Care is regulated as per the Instruction of Ordinance on Uniform State Requirements OUSR (3). The school discipline Palliative Nurse Care is incorporated as a mandatory one, in the curriculum of the program 7.5.1 Nurse from the professional direction 7.5 Health Care in the field of higher education 7.1 Healthcare and Sports, for a Bachelor's degree. The subject comprises a workload of 30 classes, of which 15 classes of lectures and 15 classes of practical exercises, studied during the sixth semes- ter. The curriculum's annotation has the aims, tasks and the discipline's place in the students' comprehensive training, described. The planned lecture subjects provide the performance of the set purposes and tasks of the training. The subjects for practical exercises are aimed at forming specific skills and competence. A use of visual and verbal scales for assessing the typical symptoms for patients with palliative trend, is being stipulated. The developed nursing documentation for the aims of training, which has to do with registering the performed clinical monitoring and assessment of the basic symptoms, provides consistency, accountancy and quality of the care. Also, scales for assessing the feeding, pain and the risk of decubitus, which are approved in the European countries, are included in the training process. The case studies covered in the training, involving ethical and moral issues related to euthanasia, the quality of life of patients and communicating the truth, allow development of the thinking and practical application of acquired knowledge in medical ethics and medical psychology. The holistic approach is the basic working principle with palliative patients. The social knowledge and basic principles of teamwork are also essential in training and practicing palliative care. While studying the discipline, especially during practical exercises, the students come across, many emotional experiences having to do with communicating the truth, the different points of view, the pros and cons regarding euthanasia, as well as palliative care for children. The role of the lecturer is to show the different points of view of the problems by applying pedagogical skills and using psychological techniques for lowering the stress during the training process.

\section{MATERIALS AND METHODS}

The used methods are: literature analysis and synthesis of specialized literature, searching for information from Internet sources; development of nursing documentation and approbation; a survey method.

\section{RESULTS AND DISCUSSION}

The content of the lectures, developed for the aim of training, provides knowledge about the nature, the basic principles, tasks and aspects of palliative care. Different points of view having to do with 
the philosophy of life and death are being considered, as well as the ethical and psycho-social problems of palliative care. Information about the interdisciplinary team who gives palliative care (PC), and the nurse's job description in terms of palliative care, is introduced. The types of organizational forms of palliative care are also introduced. The PC for patients in a hospice is considered in detail. The basic symptoms and syndromes of terminally ill people are differentiated, and there are also an assessment, treatment and nurse care included. Palliative care for somatically ill people is organized in a way to cover all human body systems. Feeding in PC, as well as the assessment and the battle with pain in the end of life in palliative medical science, are the next topics included in the training process. Side effects from the oncological treatment and the psychological problems of the nurse who works with terminally ill patients, is part of the specificity of the discipline. The topic The Cehild as a Patient Who Needs Palliative Care is being introduced vastly and in detail.

The amount of theoretical material provides enough knowledge for the nature and the basic principles of the Palliative Medical Science, as well as for the organizational forms, and the role of every member from the palliative care team.

The practical exercises include: working with medical documentation and developed nursing documentation, for the goal of the training, communication with the ill ones and their relatives; discussing clinical cases.

The practical exercises are being held in a real environment at the Palliative Care ward at the Complex Cancer Center (CCC) in Ruse. Working in small groups provides opportunity for active participation of all the students in the exercises. The topics of the practical exercises, are revealed at the end of the previous class. The preliminary preparation gives knowledge on the subject and opportunity for clinical work with patients. The topics of practical exercises are aimed at: differentiation between the regular and palliative care, considering the roles of the members of the palliative care team, and a detailed discussion and acquaintance with the nurse's job description. Forming an assessment and clinical monitoring of the basic symptoms, acquaintance and work with a specially developed nursing documen- tation for the purpose, which includes: protocols for evaluation of the clinical symptoms and registration cards for the results obtained, as well as an electronic nurse file. All stages of the nursing process are practically applied, as it stressed on the evaluation of needs and planning of individual nurse care. In connection with the assessment of the risk of decubitus, a specially developed scale of Waterlow is being used, and preventive activities and measures are done in practice. For pain assessment, the students acquaint themselves with, and work with standardized verbal and analog scales. During the exercises the students work out a clinical evaluation and nurse care of individuals with anorexia/cachexia syndrome (ACS), and apply the Rules of Conduct as per Clinical path №253. For accomplishing the exercises, which deal with palliative care for children, discussion of cases is planned, as well as working in small groups and roleplay. While dealing with the electronic nurse file, the students have the opportunity to suggest ideas for optimizing the process of nurse care and activities documentation.

A feedback in the form of a survey of satisfaction and quality of the students training, was achieved after a-course for undergraduate students from the Nurse program of the University of Russe "Angel Kanchev". 30 students are being asked the question: Do you think the information you have studied during your training in Palliative Care is sufficient in both theoretical and practical aspect: $88 \%$ of them are fully satisfied and think that the amount of information is enough and gives basic knowledge on the subject; $10 \%$ of them think that the amount of information is enough, but it's hard to understand, and $2 \%$ of the respondents think that more information is needed.

Most evocative are the exercises, which include the ethics principles and tasks for the palliative care. The topics considering death and the process of dying, are being perceived with negative emotions. After the training process, the students' opinion of the concept of best death was researched, $60 \%$ of them have classified the answers in the following way: uppermost they have pointed out death in sleep, second death in s.o.'s own house, or surrounded by his relatives, third painless death, and finally, sudden death. All students' general opinion is that patients should choose where they die. Figure 1 shows the answers of 
students on where it is best for the patients to meet their own death.

\section{End of life}

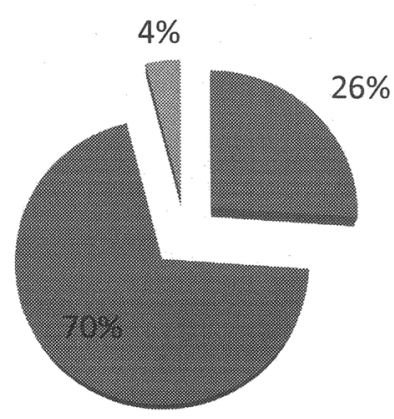

At his/her home in privacy.

At his/her home surrounded by his/her relatives.

- At a hospice or ward for palliative care.

Fig. 1. Location of death

Figure 2 visualizes the students' opinion on the patient dying in his/her house.

\section{Occurring of death at the patient's house}

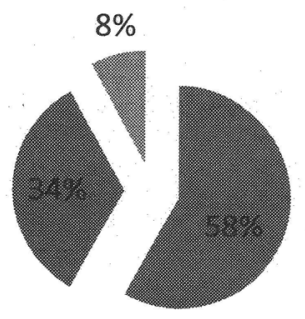

a supportive
environment
opportunity of
free visiting
saving ones
dignity

Fig. 2. What brings the oncoming of death at the patient's house

According to $58 \%$ of the respondents the death at the patient's house will give them supportive environment, $8 \%$ think that this will provide free visits by the relatives and time to say goodbye with them, and $34 \%$ of the respondents think that death at the patients' house will help them keep their dignity. In connection with the cases that deal with communicating the truth, the nature and perspectives of the patients' disease as well as their option of choosing, all students have given an affirmative response.
In connection with the considered "for" and "against" points of view, of applying euthanasia and assisted suicide to patients with unfavorable prognosis of disease, $65 \%$ of the students support the idea of legal regulation and applying euthanasia and assisted suicide. Figure 3 shows the students' researched opinion of "for" and "against" applying euthanasia and assisted suicide.

\section{Applying of euthanasia and assisted suicide}

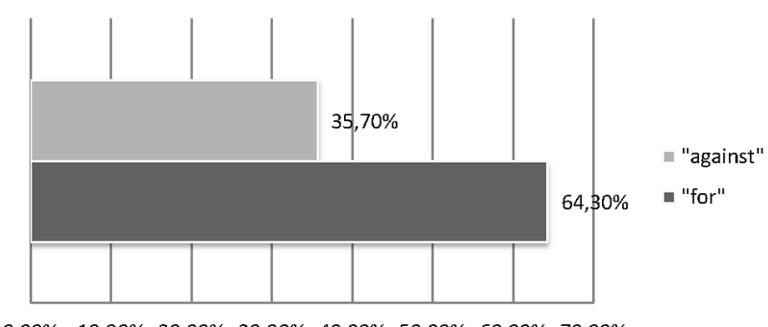

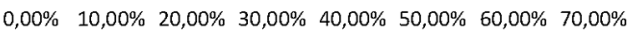

Fig. 3. "For" and "against" applying euthanasia and assisted suicide

The students' arguments for applying euthanasia are that life prolongation of patients on account of life's quality is unacceptable, and that everyone has the right to choose how one should die. In their arguments, the students give an explicit condition, that euthanasia can only be applied to terminally ill people and that it should be legally regulated, whence that will make abuse impossible.

The approbation of the developed nursing documentation from the team of palliative care trainers was accomplished at the Palliative Care ward at CCC-Ruse during the practical exercises. By the students' opinion survey it was found that $90 \%$ of them consider the developed documentation as useful. Their answers are arranged by importance: uppermost they have pointed out, that the introduction of this documentation will increase the quality of patients care, secondly-the nurse's job will be made easier this way, and thirdly-registering the daily activities done by the nurse, will become possible this way. Only one of the students thinks this documentation is completely useless. The opinion survey for the necessity of making an assessment of the risk of decubitus on the Waterlow scale is very important for the nurse's organization of work, as it is set as an activi- 
ty in CP 253(4). Most of the respondents (75\%) think that the Waterlow scale is necessary, because it registers risk of seemingly non-risky patients, and by applying preventive measures, money given for decubitus wounds treatment would be spared, as well as for preserving the quality of life.

The last question of the survey is aimed at exploring the students' attitude towards working in a palliative care ward. Figure 4 reflects their answers, as well as the conditions under which they would start working in this sphere of healthcare.

\section{A palliative care ward as a place of work}
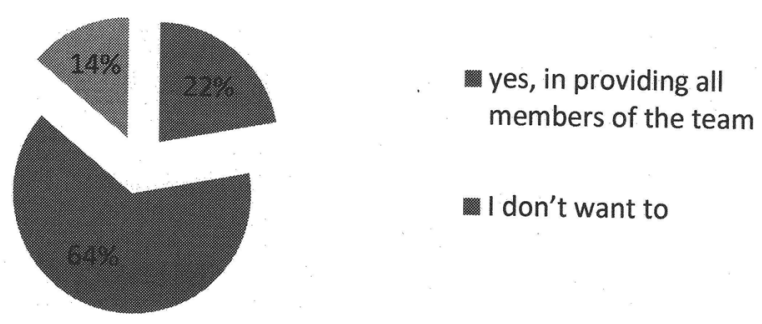

I don't want to

Fig. 4. Choice of palliative care ward as a place of work

As seen from the results, $64 \%$ of the respondents at this stage of training, do not wish to work in this sphere. At the end of third year of education, a great part of the students have already made their future professional choice. The rest of them make their final decision after carrying out their internship. We find that the variety of problems, the plight and the lack of perspective from the treatment, as well as encounters with death, are some of the reasons why the trainees do not wish to work, in the sphere of palliative care. Part of the respondents (22\%) would accept working with palliative patients, provided all members of the palliative care team are present - a doctor, a psychologist, a caseworker, and volunteers.

\section{CONCLUSIONS}

The palliative nurse care is a complex and interdisciplinary direction which requires specific preparation and certain personal qualities. The lack of clinical discipline of Palliative Care in the nurses' training, puts a serious challenge to the palliative nurse care training team to introduce the discipline to the students.
The amount and content of the planned thematic units in the training process, guarantees the students' acquaintance with basic knowledge, forming of skills and competence for working with patients who need palliative care. A positive feedback as well as enough amount of the provided information, are being determined by the performed inquiry among students, who have passed a course in Palliative Nurse Care. The constant development of science, as well as every direction in health care, requires continuing education and acquisition of new knowledge, skills and competence.

\section{REFERENCES}

1. WHO.Definition of palliative care. 1990. http://64.85.16.230/educate/content/elements/ whodefinition

2. NATIONAL HEALTH STRATEGY http://www.mh.government.bg/bg/ politiki/strategii-i-kontseptsii/strategii/ nacionalna-zdravna-strategiya-2014-2020/

3. ORDINANCE ABOUT THE UNIFORM STATE REQUIREMENTS FOR ACQUISITION OF HIGHER EDUCATION FOR THE DISCIPLINES NURSE, MIDWIFE,AND PHYSICIAN ASSISTANT FOR BACHELOR DEGREE

4. Clinical path №253 Palliative care for cancer-ill patients http://www.hapche.bg/zakonodatelstvo/sluzheben-ramkov-dogovor-2016-za-meditsinskitedeynosti-prilozhenie-11-klinichna-pateka-kp-253 